\title{
ANALISIS KEPUASAN PASIEN RAWAT JALAN TERHADAP MUTU PELAYANAN KEFARMASIAN DI PUSKESMAS TANAWANGKO
}

\section{OUTPATIENT SATISFACTION ANALYSIS ON THE QUALITY OF PHARMACEUTICAL SERVICES AT THE TANAWANGKO HEALTH CENTER}

\author{
Greey Cendi Elsa Bunet ${ }^{1)}$, Widya Astuty Lolo ${ }^{1)}$, Erladys M. Rumondor ${ }^{1)}$ \\ ${ }^{1)}$ Program Studi Farmasi FMIPA UNSRAT Manado, 95115 \\ *elsabunet999@gmail.com
}

\begin{abstract}
Patient satisfaction is an important indicator for pharmaceutical services and has a close relationship with service quality. A good quality of services will provide satisfaction to patient so that it affects to return the Health Center. The purpose of this study was to determine the satisfaction of outpatients with the quality of pharmaceutical services at the Tanawangko Health Center. This research is a descriptive study and the data collection tool used is the questionnaire given to 277 respondents. Based on the research results obtained, it is known that each question on the 5 dimensions has a negative value with an average value (-0.38) this value is obtained from the average value of the total service quality index between expectations and reality, meaning the patient is not satisfied. The reality received is lower yhan expectations.
\end{abstract}

Keywords : Level of satisfaction, expectations, reality.

\begin{abstract}
ABSTRAK
Kepuasan pasien merupakan indikator penting bagi pelayanan kefarmasian dan memiliki hubungan erat dengan kualitas pelayanan. Kualitas pelayanan yang baik akan memberikan kepuasan kepada pasien sehingga mempengaruhi pasien untuk kembali lagi ke Puskesmas. Tujuan dari penelitian ini untuk mengetahui kepuasan pasien rawat jalan terhadap mutu pelayanan kefarmasian di Puskesmas Tanawangko. Penelitian ini merupakan penelitian deskriptif dan alat pengumpulan data yang digunakan yaitu kuesioner diberikan kepada 277 responden. Berdasarkan hasil penelitian yang diperoleh, diketahui bahwa setiap pertanyaan pada 5 dimensi memiliki nilai negatif dengan nilai rata-rata $(-0,38)$ nilai ini diperoleh dari rata-rata nilai indeks total kualitas pelayanan antara harapan dan kenyataan, artinya pasien tidak puas. Kenyataan yang diterima lebih rendah dibandingkan dengan harapan.
\end{abstract}

Kata Kunci : Tingkat kepuasan, harapan, kenyataan. 


\section{PENDAHULUAN}

Pusat kesehatan masyarakat adalah pelayanan kesehatan yang menyelenggarakan upaya kesehatan masyarakat dan upaya kesehatan perserorangan tingkat pertama dengan lebih mengutamakan peningkatan kesehatan (promotif), dan pencegahan penyakit (preventif) tanpa mengabaikan upaya penyembuhan penyakit (kuratif) dan pemulihan kesehatan (rehabilitatif) untuk mencapai derajat kesehatan setinggi-tingginya di wilayah kerjanya (Permenkes, 2014).

Pelayanan kefarmasian merupakan kegiatan yang terpadu dengan tujuan untuk mengidentifikasi, mencegah, menyelesaikan masalah obat dan masalah yang berhubungan dengan kesehatan. Tuntutan pasien dan masyarakat akan peningkatan mutu pelayanan kefarmasian mengharuskan adanya perluasan dari paradigma lama yang berorientasi kepada produk (drug oriented), menjadi paradigma baru yang berorientasi pada pasien (patient oriented) dengan filosofi pelayanan kefarmasian (pharmaceutical care) (Permenkes 2016).

Tingkat kepuasan pasien adalah perasaan pasien yang timbul dari kinerja layanan kesehatan yang diperoleh setelah membandingkan dengan apa yang dirasakan. Tingkat kepuasan pasien ditinjau dari lima dimensi servqual yakni dimensi kehandalan (reliability) adalah kemampuan memberikan pelayanan yang memuaskan paien. Dimensi ketanggapan (responsiveness) adalah kemampuan membantu pasien dan memenuhi permintaan mereka. Dimensi jaminan (assurance) adalah kemampuan untuk menimbulkan kepercayaan dan rasa aman. Dimensi empati (epathy) adalah perhatian secara personal kepada konsumen. Dimensi berwujud (tangible) adalah sarana dan fasilitas fisik (Kevin, 2016).

Menrut penelitian yang dilakukan oleh Dasmiwarita (2012) menunjukkan hasil bahwa pasien lebih merasa puas pada dimensi berwujud (tangible) sebesar $82 \%$, dibandingkan kepuasan pasien pada dimensi ketanggapan (responsiveness) sebesar $28 \%$. Dengan demikian kepuasan pasien lebih banyak ditunjang oleh kondisi lingkungan dibandingkan pelayanan kesehatan.

Kualitas pelayanan kesehatan memiliki hubungan yang erat dengan kepuasan pasien. Jika kenyataan melebihi harapan maka pasien akan menggunakan pelayanan kesehatan tersebut kembali. Berdasarkan latar belakang di atas peneliti tertarik untuk melakukan penelitian tentang analisis kepuasan pasien rawat jalan terhadap mutu pelayanan kefarmasian di Puskesmas Tanawangko.

\section{METODOLOGI PENELITIAN Waktu dan Tempat Penelitian}

Penelitian ini dilakukan pada bulan Desember 2019 - Juli 2020 di Puskesmas Tanawangko.

\section{Jenis Penelitian}

Penelitian ini meruapakan penelitian deskriptif. Pengumpulan data menggunakan kuesioner yang diberikan pada pasien rawat jalan di Puskesmas Tanawangko.

\section{Alat dan Bahan}

Alat

Alat yang digunakan pada penelitian ini adalah kamera untuk dokumentasi dan alat tulis menulis, lembar kuesioner,

\section{Bahan}

Data yang digunakan terdiri dari dua sumber data yaitu :

1. Data primer diperoleh dari hasil kuesioner yang diisi oleh responden.

2. Data sekunder berupa pengumpulan data yang dilakukan melalui jurnal dan studi bahan kepustakaan yang perlu untuk mendukung data primer.

\section{Populasi Penelitian}

Populasi dalam penelitian merupakan wilayah yang ingin diteliti yang terdiri atas objek/subjek yang mempunyai kualitas dan karakteristik tertentu yang ditetapkan oleh peneliti untuk dipelajari dan kemudian ditarik kesimpulannya (Sugiyono, 2016). Populasi dalam penelitian ini adalah seluruh pasien 
rawat jalan yang mendapatkan pelayanan kefarmasian di Puskesmas Tanawangko

\section{Sampel Penelitian}

Pengumpulan sampel dalam penelitian ini menggunakan metode non-probability sampling. Dalam hal ini objek penelitian dianggap paling tahu tentang apa yang kita harapkan sehingga mudah untuk mengganti objek yang diteliti. Sampel yang digunakan ialah pasien rawat jalan yang berobat di puskesmas Tanawangko yang memenuhi kriteria inklusi dan eksklusi.

1. Kriteria Inklusi :

a. Pasien rawat jalan yang bersedia

b. Pasien dewasa $\geq 17$ tahun ke (Depkes, 2009).

2. Kriteria Eksklusi :

a. Pasien yang tidak bisa baca tulis.

Rumus yang digunakan untuk menghitung besaran sampel menggunakan rumus Slovin:

Keterangan :

$$
n=\frac{N}{1+N e^{2}}
$$

$\mathrm{n}=$ Besar sampel

$\mathrm{N}=$ Jumlah populasi

$\mathrm{e}=$ Persentase kelonggaran ketelitian pengambilan sampel yang masih ditolelir 5\% $(0,05)$.

Dalam penelitian ini jumlah sampel yang digunakan dalam perhitungan sebanyak 277 responden/pasien rawat jalan yang berkunjung di Puskesmas Tanawagko selama satu bulan.

\section{Analisis Data}

Pengumpulan data menggunakan kuesioner berdasarkan lima dimensi yaitu Tangible, Realiability, Responsiveness, Assurance, Empathy. Semua jawaban diberi skor berdasarkan skala Likert. Dengan tingkat penilaian sebagai berikut :
1. Sangat puas $=4$
2. Puas $=3$
3. Kurang puas $=2$
4. Tidak puas $=1$

Dalam menganalisis data menggunakan rumus sebagai berikut :

$$
x=\frac{\sum x i}{n} \quad y=\frac{\sum y i}{n}
$$

Keterangan :

$\mathrm{x}=$ Skor rata-rata kenyataan/kinerja.

$\mathrm{y}=$ Skor rata-rata harapan.

$\sum x i=$ Jumlah skor item pernyataan kenyataan.

$\sum y i=$ Jumlah skor item pernyataan harapan

Analisis yang digunakan untuk menghitung total kualitas pada penelitian ini menggunakan model Weighted Servqual sebagai berikut :

$$
I k j=\sum_{I=0}^{n}(P i j-E i j)
$$

Keterangan :

Ikj = Indeks total kualitas pelayanan.

Pij = Perfomance I pada objek $\mathrm{J}$.

Eij = Expectance (harapan atribut pada objek j).

$\mathrm{n} \quad=$ Jumlah pernyataan (Priyatno, 2010).

\section{Uji Validitas dan Reliabilitas Uji Validitas}

Uji validitas bertujuan untuk mengetahui kuesioner yang dibuat tepat dan dapat digunakan untuk sebuah penelitian. Uji ini dilakukan dengan cara membandingkan angka $r$ hitung dan $r$ tabel. Jika $r$ hitung lebih besar dari $r$ tabel maka item dinyatakan valid dan sebaliknya jiks $r$ hitung lebih kecil dari $r$ tabel maka item dikatakan tidak valid (Sugiyono, 2016)

\section{Uji Reliabilitas}

Reliabilitas adalah indeks yang menunjukkan sejauh mana suatu alat pengukur dapat dipercaya atau diandalkan. Jika suatu alat pengukur dipakai dua kali untuk mengukur gejala yang sama dan hasil pengukuran yang diperoleh relative konsisten maka alat tersebut reliabel (Sugiyono, 2016).

Uji reliabilitas dilakukan dengan cara membandingkan angka Cronbach alpha dengan ketentuan nilai Cronbach alpha. Suatu kuesioner dikatakan reliabel jika jawaban seseorang terhadap pernyataan adalah konsisten atau stabil dari waktu ke waktu. (Notoadmodjo, 2012). 
HASIL DAN PEMBAHASAN

Karakteristik Responden

Tabel 1. Karakteristik Pasien Puskesmas Tanawangko

\begin{tabular}{|c|c|c|}
\hline \multirow{2}{*}{ Karakteristik } & \multicolumn{2}{|l|}{ Total } \\
\hline & $\mathbf{n}$ & $(\%)$ \\
\hline \multicolumn{3}{|l|}{ Jenis Kelamin } \\
\hline Perempuan & 180 & 64,9 \\
\hline Laki-laki & 97 & 35,1 \\
\hline \multicolumn{3}{|l|}{ Usia (Depkes, 2009) } \\
\hline (17 - 25 Tahun $)$ & 42 & 15,1 \\
\hline (26 - 35 Tahun) & 59 & 21,2 \\
\hline (36 - 45 Tahun) & 50 & 18 \\
\hline (46 - 55 Tahun) & 61 & 22 \\
\hline (56 - 65 Tahun) & 45 & 16,2 \\
\hline (>65 tahun) & 20 & 7,2 \\
\hline \multicolumn{3}{|l|}{ Pendidikan Terakhir } \\
\hline $\mathrm{SD}$ & 41 & 14,8 \\
\hline SMP & 80 & 28,8 \\
\hline SMA & 130 & 46,9 \\
\hline Diploma/Sarjana & 23 & 8,3 \\
\hline Lainnya & 3 & 1 \\
\hline \multicolumn{3}{|l|}{ Jenis Pekerjaan } \\
\hline Tidak & 161 & 58,1 \\
\hline Bekerja/IRT & & \\
\hline Wiraswasta & 15 & 5,4 \\
\hline Buruh / Karyawan & 25 & 9 \\
\hline Petani & 40 & 14,4 \\
\hline Pengajar & 7 & 2,5 \\
\hline PNS & 6 & 2,1 \\
\hline Lainnya & 23 & 8,3 \\
\hline
\end{tabular}

responden terbanyak adalah perempuan 180 pasien $(64,9 \%)$ dan jenis kelamin laki-laki sebanyak 97 pasien $(35,1 \%)$. Menurut Notoatmodjo (2012), penggunaan pelayanan kesehatan oleh perempuan lebih tinggi dibandingkan dengan laki-laki, ini dikarenakan perempuan mempunyai resiko penyakit yang lebih besar dibandingkan dengan laki-laki. Hal ini sejalan dengan penelitian yang dilakukan oleh Kurniawati (2019) di Kecamatan Glagah Kabupaten Lamongan bahwa perempuan lebih peduli terhadap kesehatan karena bukan hanya untuk dirinya sendiri melainkan untuk anak-anak dan keluarganya.

Karakteristik responden berdasarkan usia didominasi oleh kelompok usia 46-55 yaitu sebesar 61 pasien (22\%). Menurut Peter (2000), kelompok umur yang berbeda memberikan perilaku berbeda. Umur dewasa memiliki cara berpikir dan mengambil keputusan yang bijak.

Karakteristik responden berdasarkan pendidikan menunjukan bahwa sebagian besar responden berpendidikan terakhir SMA yaitu sebanyak 130 pasien $(46,9 \%)$. Menurut Jacobalis (2000), tingkat pendidikan dapat mempengaruhi pola pikir rasional dan irasional seseorang dalam mengambil keputusan, menggunakan, atau memanfaatkan suatu pelayanan kesehatan. Pengetahuan dan harapan seseorang terhadap pelayanan akan meningkat ketika tingkat pendidikan mereka semakin tinggi, sehingga tingkat kepuasan seseorang dengan pendidikan tinggi akan menurun ketika harapan tidak terpenuhi.

Karakteristik responden berdasarkan pekerjaan terbanyak adalah 161 paasien (58\%) tidak bekerja. Mayoritas responden yang tidak bekerja adalah berjenis kelamin perempuan. Mayoritas responden kebanyakan adalah ibu rumah tangga (IRT), sehingga kesediaan meluangkan waktu untuk pelayanan kesehatan juga lebih besar dibandingkan laki-laki. Pekerjaan dan keadaan ekonomi suatu keluarga dapat berpengaruh besar terhadap perilaku konsumen.

\section{Uji Validitas Kuesioner}

Uji validitas kuesioner diberikan kepada 30 responden pada awal peelitian. Berdasarkan hasil yang diperoleh diketahui bahwa item 1 sampai 23 pada kuesioner harapan dan kenyataan dinyatakan valid karena nilai $r$ hitung melebihi nilai $r$ tabel.

\section{Uji Reliabilitias Kuesioner}

Berdasarkan hasil perhitungan menggunakan software SPPS diketahui bahwa semua item pada kuesioner harapan dan kenyataan dinyatakan reliabel dilihat dari nilai koefisien Cronbach's alfa $(\geq 0,6)$. 


\section{Analisis Secara Keseluruhan Tingkat Kepuasan Pasien Rawat Jalan di Puskesmas Tanawangko}

Tabel 2. Perhitungan Keseluruhan Tingkat Kepuasan Pasien Rawat Jalan di Puskesmas Tanawangko.

\begin{tabular}{|c|c|c|c|c|c|c|c|c|}
\hline Dimensi & Item & $\begin{array}{l}\text { Harapa } \\
\text { n }\end{array}$ & $\begin{array}{l}\text { Kenyata } \\
\text { an }\end{array}$ & $\begin{array}{l}\text { Rata-rata } \\
\text { Harapan }\end{array}$ & $\begin{array}{c}\text { Rata-rata } \\
\text { Kenyataan }\end{array}$ & Ikj & $\begin{array}{l}\text { Rata- } \\
\text { rata } \\
\text { Per } \\
\text { Dimens } \\
\text { i }\end{array}$ & $\begin{array}{c}\text { Pering } \\
\text { kat }\end{array}$ \\
\hline \multirow[t]{5}{*}{ Tangibles } & 1 & 1058 & 889 & 3,82 & 3,21 & $-0,61$ & $-0,42$ & 3 \\
\hline & 2 & 1003 & 840 & 3,62 & 3,03 & $-0,59$ & & \\
\hline & 3 & 1049 & 988 & 3,79 & 3,57 & $-0,22$ & & \\
\hline & 4 & 1042 & 961 & 3,76 & 3,47 & $-0,29$ & & \\
\hline & 5 & 1033 & 925 & 3,73 & 3,34 & $-0,39$ & & \\
\hline \multirow[t]{5}{*}{ Reliability } & 1 & 1089 & 996 & 3,93 & 3,60 & $-0,34$ & $-0,26$ & 1 \\
\hline & 2 & 1072 & 1091 & 3,94 & 3,94 & $-0,07$ & & \\
\hline & 3 & 1083 & 944 & 3,91 & 3,41 & $-0,50$ & & \\
\hline & 4 & 1083 & 990 & 3,91 & 3,57 & $-0,34$ & & \\
\hline & 5 & 1080 & 1029 & 3,90 & 3,71 & $-0,18$ & & \\
\hline \multirow{5}{*}{$\begin{array}{l}\text { Responsiv } \\
\text { eness }\end{array}$} & 1 & 1087 & 925 & 3,92 & 3,34 & $-0,58$ & $-0,45$ & 4 \\
\hline & 2 & 1081 & 936 & 3,90 & 3,38 & $-0,52$ & & \\
\hline & 3 & 1074 & 964 & 3,88 & 3,48 & $-0,40$ & & \\
\hline & 4 & 1078 & 1007 & 3,89 & 3,64 & $-0,26$ & & \\
\hline & 5 & 1079 & 939 & 3,90 & 3,39 & $-0,51$ & & \\
\hline \multirow[t]{5}{*}{ Assurance } & 1 & 1089 & 1012 & 3,93 & 3,65 & $-0,28$ & $-0,45$ & 5 \\
\hline & 2 & 1068 & 953 & 3,86 & 3,44 & $-0,42$ & & \\
\hline & 3 & 1075 & 917 & 3,88 & 3,31 & $-0,57$ & & \\
\hline & 4 & 1075 & 904 & 3,88 & 3,26 & $-0,62$ & & \\
\hline & 5 & 1059 & 958 & 3,82 & 3,46 & $-0,36$ & & \\
\hline \multirow[t]{3}{*}{ Empaty } & 1 & 1076 & 987 & 3,88 & 3,56 & $-0,32$ & $-0,32$ & 2 \\
\hline & 2 & 1059 & 979 & 3,82 & 3,53 & $-0,29$ & & \\
\hline & 3 & 1080 & 980 & 3,90 & 3,54 & $-0,36$ & & \\
\hline
\end{tabular}

Nilai Kepuasaan Secara Keseluruhan

$-0,38$

Berdasarkan Tabel 14 dapat dilihat bahwa secara keseluruhan terdapat dua dimensi yang mencolok. Pada nilai indeks total kualitas pelayanan (Ikj) terendah ditempati oleh dimensi kehandalan dan nilai Ikj tertinggi ditempati oleh dimensi ketanggapan dan jaminan.

Kuesioner pada dimensi kehandalan (reliability) menempati urutan pertama diantara dimensi lainnya. Pada dimensi terdapat 5 item pernyataan dengan nilai $\mathrm{Ikj}$ tertinggi terdapat pada item $3(-0,50)$ dan nilai Ikj terendah pada item item $2(-0,07)$ dengan rerata nilai Ikj dimensi kehandalan adalah $(-0,26)$, artinya nilai gap termasuk kategori negatf sehingga memberikan hasil yang kurang memuaskan untuk responden. Hal ini dikarenakan banyaknya pasien yang mengantri untuk mendapatkan pelayanan sehingga petugas di Puskesmas tidak 
menjelaskan tentang efek samping obat yang diberikan kepada pasien. Sesuai dengan Permenkes nomor 74 tahun 2016, beban kerja apoteker di Instalasi Farmasi Rumah Sakit yaitu rasio 1 apoteker untuk 50 pasien rawat jalan. Dilihat pada jumlah apoteker yang bertugas di Puskesmas Tanawangko hanya 1 apoteker membuat petugas memberikan pelayanan kepada pasien menjadi kurang sedangkan pasien banyak yang mengantri sehingga membuat responden merasa kurang puas.

Kuesioner pada dimensi empati menempati urutan kedua dan terdapat 3 item pertanyaan dengan nilai Ikj tertinggi terletak pada item $3(-0,36)$ dan nilai Ikj terendah pada item 2 (-0,29). Secara keseluruhan pasien belum puas dengan dimensi empati, ini terlihat dengan rata-rata nilai Ikj yang menunjukan nilai negatif yaitu $-0,32$. Perlu adanya pelatihan dalam hal keterampilan pada petugas khususnya menyangkut interkasi dan komunikasi agar pasien merasa nyaman dalam berkomunikasi dengan petugas (Isnandar, 2013).

Kuesioner pada dimensi berwujud (Tangible) menempati urutan 3 dan memiliki 5 item pertanyaan dengan nilai Ikj tertinggi pada item $1(-0,61)$ dan nilai Ikj terendah terdapat pada item $3(-0,22)$. Rata-rata nilai Ikj pada dimensi berwujud adalah $(-0,42)$ artinya nilai gap termasuk kategori negatif. Berdasarkan analisa, seharusnya pihak puskesmas lebih memperhatikan untuk melengkapi fasilitas seperti membersihkan ruang tunggu agar terihat bersih dan rapi, begitu juga dengan fasilitas seperti tempat duduk yang dirasa pasien masih kurang agar ditambah sehingga pasien yang mengantri mendapatkankan kenyamanan selama di Puskesmas.

Kuesioner pada dimensi ketanggapan diwakili oleh 5 item pertanyaan denga nilai Ikj tertinggi pada item $1(-0,58)$ dan nilai Ikj terendah pada item $4(-0,26)$ dengan rata-rata nilai Ikj sebesar $(-0,45)$, nilai ini terdapat pada rentang negatif pada klasifikasi gap. Pasien belum merasa puas dikarenakan petugas belum menangani keluhan mereka, ini disebabkan oleh pasien yang datang pada jam yang bersamaan pada pagi hari sehingga terjadi antrian dan menyebabkan pelayanan yang diberikan kurang puas hal ini didukung dengan kondisi apoteker yang hanya seorang diri sehingga obat yang diberikan kepada pasien tidak tepat waktu. Kepuasan terhadap ketepatan waktu dapat membuat responden merasa puas dan senang dan komunikasi yang baik dengan pasien akan membentuk persepsi yang lebih positif. responden belum merasa puas pada item 1 yaitu petugas cepat tanggap menangani keluhan pasien dengan nilai ikj 0,58 . Hal ini terjadi dikarenakan banyaknya pasien yang datang pada jam yang bersamaan sehingga terjadi penumpukkan pasien yang membuat apoteker yang bertugas menjadi lambat dalam menangani keluhan pasien.

Kuesioner pada dimensi jaminan (assurance) memiliki 5 item pertanyaan dengan nilai Ikj tertinggi terdapat pada item 5 $(-0,62)$ dan nilai Ikj terendah terdapat pada item $1(-0,28)$ dan memiliki nilai rata-rata Ikj sebesar $(-0,45)$ dan secara keseluruhan pasien belum merasa puas pada dimensi ini dikarenakan obat yang dibutuhkan tidak selalu tersedia. Hasil wawancara pada beberapa responden diketahui bahwa sering terjadi kekurangan obat yang berdampak pada tidak tersedianya obat sesuai dengan kebutuhan pasien sehingga sering disarankan untuk membeli obat di apotek.

Analisis secara keseluruhan rata-rata nilai Ikj semua item pada setiap dimensi diperoleh nilai -0,38. Nilai kepuasan ini terletak pada rentang negatif, yang artinya harapan yang dirasakan pasien lebih besar dibandingkan kenyataan yang diterima. Nilai ini menyebabkan kualitas pelayanan menjadi tidak sesuai dengan harapan pasien dan menyebabkan pasien tidak puas terhadap pelayanan kefarmasian di Puskesmas. Harapan pasien yang sangat tinggi terhadap pelayanan yang ingin diperoleh menyebabkan nilai Ikj total menjadi negatif, walaupun pada kenyataannya rata-rata jawaban responden sebagian besar memilih puas terhadap semua item. 


\section{KESIMPULAN}

Berdasarkan penelitian yang dilakukan, diperoleh rata-rata kepuasan pasien sebesar $(-0,38)$ shingga disimpulkan bahwa tingkat kepuasan pasien rawat jalan di Puskesmas Tanawangko terdapat pada rentan negatif yang artinya pasien tidak puas. Kenyataan yang diterima lebih rendah dibandingkan dengan harapan.

\section{SARAN}

Bagi peneliti selanjutnya disarankan untuk melakukan penelitian tentang evaluasi pengelolaan obat di Puskesmas Tanawangko.

\section{DAFTAR PUSTAKA}

Dasmiwarita. 2012. Analisis Kepuasan Pasien Rawat Jalan Puskesmas di Kabupaten Padang Pariaman, [Skripsi]. Fakultas Kesehatan Masyarakat Universitas Indonesia, Depok.

Departemen Kesehatan RI 2009. Kategori Umur. Kementrian Kesehatan Republik Indonesia, Jakarta.

Jacobalis, S. (2000). Kumpulan Tulisan Terpilih Tentang Rumah Sakit Indonesia dalam Dinamika Sejarah, Transformasi, Globalisasi dan Krisis Nasional. Yayasan Penerbit IDI, Jakarta.

Kevin, K. 2016. Marketing Management Edisi XIV. Prentice-Hall Published, New York.
Kurniawati, L. 2019. Hubungan Pengetahuan Masyarakat Terhadap Perilaku Penggunaan Antibiotik [Skripsi]. Fakultas Kedokteran dan Ilmu Kesehatan, Universitas Islam Negeri Maulana Malik Ibrahim, Malang.

Notoatmodjo, S. 2012. Metodologi Penelitian Kesehatan. Rineka Cipta. Jakarta.

Peraturan Menteri Kesehatan Republik Indonesia. 2014. Peraturan Menteri Kesehatan Nomor 74 Tahun 2014 tentang Pusat Kesehatan Masyarakat. Departemen Kesehatan Republik Indonesia, Jakarta.

Peraturan Menteri Kesehatan Republik Indonesia. 2016. Peraturan Menteri Kesehatan Nomor 74 Tahun 2016 tentang Standar Pelayanan Kefarnasian di Puskesmas. Departemen Kesehatan Republik Indonesia, Jakarta.

Peter, P. 2000. Perilaku Konsumen dan Strategi Pemasaran. Erlangga, Jakarta.

Priyatno, D. 2010. Paham Analisa Statistik Data dengan SPSS. Mediakom, Yogyakarta.

Sugiyono. 2016. Metode Penelitian Kuantitatif, Kualitatif dan Kombinasi (Mixed Methods). Alfabeta, Bandung. 